\title{
POLA KOMUNIKASI KOMUNITAS RUMAH BELAJAR SAHAJA BANDUNG (STUDI ETNOGRAFI KOMUNIKASI TENTANG POLA KOMUNIKASI ANTARA PENGAJAR DAN ANAK JALANAN DI RUMAH BELAJAR SAHAJA BANDUNG)
}

\author{
Dwi Rizqi Anta, Arie Prasetio \\ Prodi S1 Ilmu Komunikasi, Fakultas Komunikasi dan Bisnis, Universitas Telkom \\ rizqianta@gmail.com,arijatock@gmail.com
}

\begin{abstract}
Education is the right of every Indonesian child. No exception a street child who are spend most of the time on the road. One of community that works in education especially for street child is Rumah Belajar Sahaja's in Bandung community. Rumah Belajar Sahaja's community is a place for street child to get education through teaches and learn activities. In every teach and learn activity there is a pattern of communication by teachers and street child.

The purpose of this study is to form a new communication pattern between teachers and street child to attract children's learning interests. The formed communication pattern is expected to be applied in the Rumah Belajar Sahaja's community so as to attract more street children to learn. The theory review used in this research is communication, interpersonal communication, communication process, communication ethnography, and communication pattern.

This research uses ethnography method of communication based on constructivist paradigm. The results showed that the process of communication, communication components and relationships between communication components to form communication patterns of Rumah Belajar Sahaja's community. Teachers approach with street child, street child follow the rules of Rumah Belajar Sahaja's community, the teacher uses coercive communication. Food and beverages are distributed to street child who are implementing the rules of Rumah Belajar Sahaja Bandung.
\end{abstract}

Keywords: Communication Patterns, Street Child, Community 


\section{PENDAHULUAN}

Pendidikan merupakan tiang pondasi bagi suatu negara dalam tindakan untuk pembangunan suatu bangsa. Tak terkecuali untuk anak-anak, mereka membutuhkan pendidikan dan dijamin oleh negara, hal tersebut sesuai dengan Pasal 9 Ayat (1) UU No 23 Tahun 2002 tentang Perlindungan Anak menyebutkan; "Setiap anak berhak memperoleh pendidikan dan pengajaran dalam rangka pengembangan pribadinya dan tingkat kecerdasannya sesuai dengan minat dan bakatnya".

Data kependudukan dari BKKBN (Badan Kependudukan dan Keluarga Berencana Nasional) 2014 menjelaskan bahwa masih ada 31,13\% atau sekitar 134402 siswa usia 715 tahun yang tidak bersekolah di tingkat pendidikan dasar. Dari data tersebut dapat ditarik kesimpulan adanya angka putus sekolah usia wajib belajar 9 tahun di di Kota Bandung masih tinggi masih tinggi. (Sumber: aplikasi.bkkbn.go.id diakses pada 10 Februari 2017, pukul 19.45 WIB).

Dengan tingginya angka anak putus sekolah berdampak pada kehidupan sosial masyarakat, salah satunya meningkatnya angka anak jalanan. Dari data Dinas Sosial Kota Bandung, pada Februari 2014 tercatat dari sekian kota/kabupaten di Jawa Barat, jumlah anak jalanan yang ada di Kota Bandung menjadi yang tertinggi mencapai sekitar 2500 orang atau 44\% permasalahan anak jalanan ada di ibukota provinsi Jawa Barat ini.

Sesuai Undang-undang No.20 Tahun 2003 tentang Sistem Pendidikan Nasional menegaskan bahwa pendidikan dilakukan melalui tiga jalur, yaitu: pendidikan formal, pendidikan nonformal, dan pendidikan informal. Pendidikan formal dilakukan di sekolah, pendidikan nonformal dilaksanakan di masyarakat, dan pendidikan informal utamanya dilaksanakan di keluarga.

Gerakan sosial dibentuk oleh sekelompok individu yang memiliki tujuan yang sama, demi suatu perubahan. Salah satu gerakan sosial membangun sekolah gratis di Bandung yang ingin peneliti teliti adalah Rumah Belajar Sahaja yang berada dipasar Ciroyom Bandung. Rumah Belajar Sahaja merupakan komunitas yang mayoritas relawan atau pengajarnya mahasiswa dan bertahan paling lama yaitu sejak 2009 dan aktif sampai sekarang.

Dari pra-riset yang peneliti lakukan, Rumah Mimpi di Jalan Asia Afrika Bandung berdiri tahun 2011, dan masih aktif sampai sekarang.Save Street Child Bandung berdiri tahun 2011 namun kegiatan aktif yang dilakukan terakhir tahun 2016 dan sekarang sudah berhenti sementara (vacuum). Rumah Belajar Sahaja Bandung berdiri tahun 2009 dan kegiatannya masih aktif sampai sekarang.

Rumah Belajar Sahaja dianggap yang paling lama bertahan dan masih aktif sampai sekarang. Rumah Belajar Sahaja masih aktif karena memiliki kegiatan tematik setiap 
minggunnya seperti belajar calistung, bahasa Inggris, agama, kesehatan, ketrampilan dan masih banyak lagi. Rumah Belajar Sahaja juga memiliki kebudayaan yang unik dari pada komunitas anak jalan lainnya seperti, budaya memandikan anak jalanan sebelum mulai belajar, menyita lem sebelum belajar, pendekatan kekeluargaan yang intim ke setiap anak jalanan seperti para pengajar datang kerumah dan berkomunikasi dengan orang tua anak jalanan.

Rumah Belajar Sahaja merupakan sebuah rumah belajar yang didirikan untuk mendidik perilaku anak jalanan agar menjadi lebih baik, berakhlak mulia, berbudi pekerti luhur, mandiri, memperoleh Pendidikan yang layak dan dapat diterima oleh masyarakat. Rumah Belajar Sahaja pertama kali digagas di sekitar Pasar Ciroyom, Bandung. Rumah Belajar Sahaja secara resmi didirikan pada tanggal 1 juli 2009, dipimpin oleh seorang Kepala Sekolah dengan masa pengabdian kurang lebih 6 bulan.(Sumber: rubelsahaja.wordpress.com diakses pada 8 Februari 2017, pukul 20.50 WIB)

Sudarwan Danim (2010:44) mengemukakan bahwa dalam seni mengajar ada dua jenis filsafat pendidikan yang bisa terapkan yaitu Andragogi dan Pedagogi. Andragogi lebih dimaknai sebagai "the art and science of helping adult learn" (ilmu dan seni membantu orang dewasa belajar). Sedangkan pedagogi sebagai "the art and science of teaching children" (ilmu dan seni mengajar anak-anak).Walaupun sama-sama memiliki fokus dalam pembelajaran tetapi dapat dilihat bahwa ada perbedaan objek ajar.

Dalam proses kegiatan belajar mengajar yang berlangsung pada dasarnya terdapat proses komunikasi yang terjadi antara pengajar dan anak jalanan. Harold Lasswell dalam Mulyana (2007:69) mengemukakan bahwa komunikasi adalah sebuah proses yang menjelaskan siapa, mengatakan apa, dengan saluran apa, kepada siapa, dan dengan pengaruh bagaimana.

Setiap kelompok masyarakat memiliki pola komunikasi yang khas dan berbedabeda.Rumah Belajar Sahaja juga memiliki pola komunikasi yang berbeda dengan kelompok lainnya. Cara komunikasi yang diterapkan pengajar terhadap anak jalanan akan berpengaruh pada keberlangsungan kegiatan belajar mengajar.

Dari uraian di atas, hal yang menarik untuk diteliti oleh peneliti adalah pola komunikasi yang dilakukan para pengajar dan anak jalanan di Rumah Belajar Sahaja. Dengan adannya pola komunikasi diharapkan nantinya bisa diterapkan di Rumah Belajar Sahaja dan digunakan para pengajar untuk menarik minat belajar anak jalanan di pasar Ciroyom Bandung.

Dari penelitian terdahulu yang serupa dengan judul "Pola Komunikasi Komunitas Save Street Child Bandung (Studi Tentang Pola Komunikasi Pengajar Dalam Menarik Minat Belajar Anak Jalanan di Save Street Child Bandung)” Pengajar mengunakan komunikasi persuasif serta intonasi yang lembut dan sopan saat berhadapan dengan anak jalanan. 
Peneliti akan melanjutkan penelitian dengan objek yang berbeda serta cara penggunaan komunikasi pengajar yang berbeda dengan Save Street Child Bandung yaitu dengan cara komunikasi tegas dan koersif yaitu komunikasi yang memaksa dan memberikan sanksisanksi. Dengan cara ini pengajar akan menemukan hal-hal baru yang mucul dari peristiwa-peristiwa komunikasi yang terjadi di Rumah Belajar Sahaja.

\section{TINJAUAN PUSTAKA}

\section{Komunikasi}

Komunikasi adalah proses penyampaian pesan atau informasi yang dilakukan oleh komunikator atau seseorang yang memberikan pesan secara verbal maupun nonverbal kepada objek sasaran yang dituju atau yang disebut komunikan. Komunikasi bertujuan untuk mengubah, mempengaruhi atau membentuk pikiran pada komunikan yang sesuai komunikator inginkan agar tujuan dari komunikasi dikatakan berhasil.

Gerald R. Miller dalam Mulyana (2008: 69): “Komunikasi terjadi ketika suatu sumber menyampaikan suatu pesan kepada penerima dengan niat yang disadari untuk mempengaruhi perilaku penerima."

Dari teori yang dikemukakan menjelaskan bahwa dapat dikatakan terjadinya komunikasi apabila pesan yang diterima pada penerima pesan telah disampaikan dengan melalui proses transmisi dari informasi, gagasan, emosi, keterampilan dan sebagainya.

\section{Konseptual Komunikasi}

Konseptualisasi komunikasi menurut John R. Wenburg dan William W. Wilmot juga Kenneth K. Sereno dan Edward M. Bodaken dalam Mulyana (2007:67-77) tedapat tiga kerangka pemahaman mengenai komunikasi, yaitu komunikasi sebagai tindakan satuarah, komunikasi sebagai interaksi, dan komunikasi sebagai transaksi.

\section{Pola Komunikasi}

Pola komunikasi adalah suatu gambaran yang sederhana dari proses komunikasi yang memperlihatkan kaitan antara satu komponen komunikasi dengan komponen lainnya (Soekanto, 2001). Pola komunikasi diartikan sebagai bentuk atau pola hubungan dua orang atau lebih dalam proses pengiriman dan penerimaan pesan dengan cara yang tepat sehingga pesan yang dimaksud dapat dipahami.

\section{Proses Komunikasi}

Proses komunikasi, terdiri atas dua tahap. meliputi proses komunikasi primer dan proses komunikasi sekunder. (Effendy dalam Mondry, 2008: 3). 
1. Proses komunikasi secara primer, merupakan proses penyampaian pikiran dan atau perasaan seseorang kepada orang lain dengan menggunakan lambang (simbol) sebagai media.

2. Proses komunikasi sekunder, merupakan proses penyampain pesan dari seseorang kepada orang lain dengan menggunakan alat atau sarana sebagai media kedua setelah menggunakan lambang sebagai media pertama.

Penegasan tentang unsur-unsur dalam proses komunikasi itu adalah sebagai berikut:

a. Sender: Komunikator yang menyampaikan pesan kepada seseorang atau sejumlah orang.

b. Encoding: Penyandian, yakni proses pengalihan pikiran kedalam bentuk lambang.

c. Message: Pesan yang merupakan seperangkat lambang bermakna yang disampaikan oleh komunikator.

d. Media: Saluran komunikasi tempat berlalunya pesan dari komunikator kepada komunikan.

e. Decoding: Pengawasandian, yaitu proses dimana komunikan menetapkan makna pada lambang yang disampaikan oleh komunikator kepadanya.

f. Receiver: Komunikan yang menerima pesan dari komunikator.

g. Response: Tanggapan, seperangkat reaksi pada komunikan setelah diterpa pesan.

h. Feedback: Umpan Balik, yakni tanggapan komunikan apabila tersampaikan atau disampaikan kepada komunikator.

i. Noise: Gangguan tak terencana yang terjadi dalam proses komunikasi sebagai akibat diterimanya pesan lain oleh komunikan yang berbeda dengan pesan yang disampaikan oleh komunikator kepadanya.

\section{Komunikasi Antarpribadi}

Secara umum komunikasi antarpribadi dapat diartikan sebagai proses pertukaran makna antara orang-orang yang saling berkomunikasi. Komunikasi antarpribadi tidak hanya menyampaikan dan menerima pesan secara timbal balik melainkan pertukaran makna yaitu kesamaan pemahaman antara orang-orang yang berkomunikasi terhadap pesan-pesan yang digunakan dalam proses komunikasi.

Menurut Parks dalam Budyatna (2012:14) bahwa komunikasi antarpribadi merupakan bentuk komunikasi yang terutama diatur oleh norma relasional. Menurut Verderber dalam Budyatna (2012:14), komunikasi antarpribadi merupakan proses melalui mana orang menciptakan dan mengelola hubungan mereka, melaksanakan tanggung jawab secara timbal balik dalam menciptakan makna.

\section{Pendidikan Nonformal}

Berbagai definisi pendidikan luar sekolah dikemukakakan oleh para ahli, seperti yang dikemukakan oleh Napitulu (1981) dalam Sudjana (2004) bahwa pengertian Pendidikan Nonformal adalah sebagai berikut : Pendidikan nonformal adalah setiap usaha pelayanan pendidikan yang diselenggarakan di luar sistem persekolahan, berlangsung seumur 
hidup, dijalankan dengan sengaja, teratur, dan berencana yang bertujuan untuk mengaktualisasikan potensi manusia (sikap, tindak dan karya) sehingga dapat terwujud manusia seutuhnya yang gemar belajar, mengajar dan mampu meningkatkan taraf hidupnya.

\section{Etnografi Komunikasi}

Studi etnografi komunikasi adalah pengembangan dari antropologi linguistik yang dipahami dalam konteks komunikasi. Tujuan deskripsi etnografi adalah untuk memberikan pemahaman global mengenai pandangan dan nilai-nilai suatu masyarakat sebagai cara untuk menjelaskan sikap dan perilaku anggota-anggotanya. (Kuswarno, 2011:13). Objek penelitian Etnografi Komunikasi yaitu Masyarakat Tutur, Aktivitas Komunikasi, Komponen Komunikasi, Kompetensi Komunikasi, Variates Bahasa.

\section{Anak Jalanan}

Menurut Shalahuddin (2000:13), yang dimaksudkan anak jalanan adalah individu yang berumur di bawah 18 tahun yang menghabiskan sebagian atau seluruh waktunya di jalanan dengan melakukan kegiatan-kegiatan guna mendapatkan uang atau guna mempertahankan hidupnya. Jalanan yang dimaksudkan tidak hanya menunjuk pada "jalanan" saja, melainkan juga tempattempat lain seperti pasar, pusat pertokoan, taman kota, alun-alun, terminal, dan stasiun.

\section{Komunitas}

Menurut Wilbur J. Peak menyatakan bahwa komunitas bukan lagi sekadar kumpulan orang yang tinggal pada lokasi yang sama tapi juga menunjukkan terjadinya interaksi di antara kumpulan orang tersebut. Jadi, selain karena faktor-faktor fisik yakni tinggal di lokasi yang sama, komunitas itu juga bisa merupakan unit sosial yang terbentuk lantaran adanya interaksi diantara mereka. Dengan kata lain, komunitas itu bukan hanya menunjuk pada lokalitas saja melainkan juga pada struktur (Iriantara, 2007:22).

\section{Rumah Belajar Sahaja}

Rumah Belajar Sahaja Ciroyom merupakan sebuah rumah belajar yang didirikan untuk mendidik perilaku anak jalanan agar menjadi lebih baik, berakhlak mulia, berbudi pekerti luhur, mandiri, memperoleh pendidikan yang layak dan dapat diterima oleh masyarakat.

\section{Kegiatan Belajar Mengajar}

Dalam hal ini yang dimaksudkan adalah belajar berarti usaha mengubah tingkah laku. Jadi, belajar akan membawa suatu perubahan pada individu-individu yang melakukan proses belajar. Perubahan tidak hanya berkaitan dengan penambahan ilmu pengetahuan, tetapi juga bentuk kecakapan atau keterampilan, sikap, pengertian harga diri, minat, watak, dan penyesuaian diri.Jelasnya menyangkut segala aspek organisme dan tingkah laku pribadi seseorang (Sardiman, 2007: 21). 


\section{METODOLOGI PENELITIAN}

Metode yang digunakan dalam penelitian ini adalah metode studi etnografi komunikasi dengan paradigma konstruktivis. Karena metode ini dapat menggambarkan, menjelaskan dan membangun hubungan dari kategori-kategori dan data yang ditemukan.Hal ini sesuai dengan tujuan dari studi etnografi komunikasi, yakni untuk menggambarkan, menganalisis, dan menjelaskan perilaku komunikasi dari suatu kelompok sosial. Kuswarno (2011:86).

Dengan menggunakan metode penelitian ini, peneliti ingin menganalisis mengenai bahasa, komunikasi dan kebudayaannya pada satu konteks yang terjadi di kelompok masyarakat tertentu dalam hal ini yaitu kelompok masyarakat di Rumah Belajar Sahaja Bandung.

\section{HASIL DAN PEMBAHASAN}

Pada sub bab ini peneliti akan menjelaskan pola komunikasi yang terbentuk antara pengajar dan anak jalanan di Rumah Belajar Sahaja sesuai dengan tinjauan pustaka yang sudah diurakan peneliti melalui pendekatan etnografi komunikasi. Proses Komunikasi dalam Rumah Belajar Sahaja yaitu:

\section{Proses Komunikasi}

Proses komunikasi pada Rumah Belajar Sahaja dapat dejelaskan dengan proses komunikas primer dan proses komunikasi sekunder.

1. Proses Komunikasi Primer

a. Bahasa: Kegiatan belajar menggunakan bahasa Indonesia.

b. Kial (gesture): Para pengajar tidak memanjakan anak-anak jalanan

c. Gambar: Media pembelajaran lebih sering menggunakan gambar.

d. Isyarat: Anak jalanan aktif saat memimpin doa dengan cara mengangkat tangan untuk memimpin berdoa.

2. Proses Komunikasi Sekunder

a. Papan tulis: Saat kegiatan belajar, pengajar menggunakan papan tulis untuk menjangkau seluruh anak jalanan agar pesan diterima anak-anak.

b. Speaker: Speaker digunakan saat kegiatan senam untuk mempermudah kegiatan senam dan menarik minat anak-anak jalanan

2. Unsur-unsur proses Komunikasi Rumah Belajar Sahaja

a. Sender: Pengajar Rumah Belajar lebih berperan sebagai komunikator saat kegiatan belajar. 
b. Encoding: Pembagian pengajar untuk memegang dan mengawasi anak-anak jalanan agar materi belajar dapat tersampaikan dengan baik.

c. Message: Materi belajar di Rumah Belajar Sahaja lebih bertujun untuk kehidupan sehari-hari anak jalanan.

d. Media: Media yang digunakan yaitu papan tulis, alat tulis, pernak-pernik untuk prakarya dan speaker.

e. Decoding: Proses decoding pada anakjalanan seringkali terlihat terhambat atau anak-anak kurang memahami pesan yang disampaikan pengajar karena anak jalanan di Rumah Belajar Sahaja yang mayoritas anak jalanan yang kecanduan lem.

f. Receiver: Anak jalanan Rumah Belajar Sahaja leih banyak sebagai komunikan saat kegiatan belajar.

g. Response: Ketika anak-anak aktif maka akan dapat dengan mudah menrima materi belajar dan antusias saat belajar. Sedangkan ketika anak-anak pasif biasanya mereka bosan dan tidak minat untuk belajar.

h. Feedback: Umpan balik yang diberikan anak jalanan ketika mereka mampu menjelaskan kembali apa yang telah mereka pelajari

i. Noise: Lokasi kegiatan belajar Rumah Belajar Sahaja di luar ruangan sehingga banyak gangguan dan hambatan.

\section{Komponen Komunikasi Rumah Belajar Sahaja}

Komponen komunikasi menurut etnografi komunikasi adalah unit-unit komunikasi yang menunjang terjadinya satu peristiwa komunikasi.Rumah Belajar Sahaja memiliki beberapa unit komponen komunikasi yang khas.Ibrahim dalam Zakirah (2005:187) menyatakan bahwa komponen-komponen komunikasi diakronimkan dalam kata SPEAKING yang terdiri dari Setting, Participants, Ends, Act Squence, Keys, Instrumentalist, Norms of Interaction, Genre.Berikut penjelasan dari komponen komunikasi.

a. Setting: Lokasi Rumah Belajar Sahaja di pasar Ciroyom Bandung, kegiatan belajar setiap hari sabtu pukul 15.00 sampai selesai.

b. Participants: Partisipan yang ikut belajar anak jalanan dan anak sekolahan dengan rentang umum 9 tahun sampai 20 tahun. Sedangankan pengajar mayoritas mahasiswa dan mahasiswi yang masih aktif di universitas masingmasing. Rentang usianya 19 tahun sampai 25 tahun.

c. Ends: Tujuan utama hadirnya Rumah Belajar Sajaha untuk merangkul anak jalanan dan memberi ilmu pengetahuan dan keterampilan hidup

d. Act Squence: Urutan kegiatan dimulai dengan memnadikan anak jalanan, mengumpulkan lem, sholat, belajar, setelah belajar selesai pengajar akan membagikan makanan dan minuman lalu ditutup dengan evaluasi pengajar.

e. Keys: Cara menarik anak jalanan untuk ikut belajar adalah dengan cara melakukan pendekatan ke anak jalanan, membuat anak jalanan nyaman, diajak ngobrol dan diberi makan dan minuman.

f. Instrumentalist: Para pengajar menggunakan bentuk pesan yang koersif atau memaksa dengan memberi sanksi-sanksi. 
g. Norms of Interaction: Norma yang diajarkan yaitu kejujuran, tanggung jawab, minta maaf dan saling tolong menolong.

h. Genre: Cara belajar dikemas dengan cerita atau dongeng agar anak jalanan tidak bosan saat belajar.

\section{Hubungan Antar Komponen Komunikasi Rumah Belajar Sahaja}

Hubungan antar komponen komunikasi akan menjelaskan beberapa hubungan komponen komunikasi seperti hubungan antara Setting dengan Participants, hubungan antara Participants dengan Genre serta hubungan antara Instrumentalist dengan Participants. Berikut penjelelasan hubungan antara komponen komunikasi yang membentuk pola komunikasi.

a. Hubungan setting dengan Participants: Lokasi belajar Rumah Belajar Sahaja di pasar Ciroyom Bandung karena banyak anak jalanan dengan mayoritas anak yang suka nge-lem. Rumah Belajar Sahaja berkomitmen untuk merangkul anak jalanan di sekitar pasar Ciroyom.

b. Hubungan Participants dengan genre: Materi pembelajaran yang diberikan kepada anak jalanan tingkat kesulitannya lebih rendah dan anak jalanan lebih senang belajar dengan media gambar atau visual.

c. Hubungan Instumentalities dengan Participants: Cara berkomunikasi pengajar menggunakan bentuk komunikasi yang koersif atau memaksa dengan sanksisanksi. Hal ini bertujuan agak anak jalanan mempunyai mental yang kuat dan mempunyai rasa tanggung jawab.

\section{Pola Komunikasi Rumah Belajar Sahaja}

Dari hubungan antar komponen komunikasi yang dijelaskan peneliti diatas dapat dilihat bahwa proses komunikasi, komponen komunikasi dan hubungan antara komponen komunikasi akan membentuk suatu peristiwa komunikasi. Peristiwa komunikasi yang dilakukan secara terus menerus akan membentuk sebuah pola komunikasi.

Peristiwa komunikasi yang dilakukan secara terus menerus di Rumah Belajar Sahaja akan membentuk suatu pola komunikasi, pola komunikasi inilah yang disebut pola komunikasi komunitas Rumah Belajar Sahaja. Berikut ini merupakan pembahasan pola komunikasi yang terbentuk di komunitas Rumah Belajar Sahaja.

a. Pengajar melakukan pendekatan dengan anak jalanan dengan cara mengajak ngobrol.

b. Anak jalanan harus melakukan peraturan Rumah Belajar Sahaja, yaitu mandi, mengumpulkan lem, sholat dan ikut belajar.

c. Pengajar melakukan komunikasi secara koersif dan tegas, misalnya anak jalanan yang tidak mengumpulkan lem hukumannya tidak mendapatkan makan dan minum.

d. Memberikan materi belajar yang anak-anak jalanan suka, misalnya dongeng, menggambar, prakarya. 
e. Anak jalanan yang melaksanakan peraturan Rumah Belajar Sahajaakan mendapatkan makan dan minum.

\section{SIMPULAN}

Berdasarkan hasil penelitian dan pembahasan mengenai pola komunikasi komunitas Rumah belajar Sahaja Bandung. Khususnya melalui kegiatan observasi partisipan selama empat bulan, dari bulan Februari sampai bulan Mei 2017, wawancara mendalam dengan para informan, maka dapat ditarik simpulan sebagai berikut:

1. Proses komunikasi pengajar dan anak jalanan di komunitas Rumah Belajar Sahaja menggunakan proses komunikasi primer yaitu dalam berkomunikasi menggunakan bahasa Indonesia, anak jalanan lebih senang belajar dengan media gambar, para pengajar tidak memanjakan anak jalanan, anak jalanan aktif saat kegiatan belajar. Sedangkan proses komunikasi sekunder berupa kegitan belajar menggunakan papan tulis untuk menjangkau semua anak jalanan agar pesan diterima oleh anak jalanan, menggunakan speaker untuk menarik minat anak jalanan.

2. Komponen-komponen komunikasi di komunitas Rumah Belajar Sahaja membangun suatu peristiwa komunikasi yang terjadi antara pengajar dan anak jalanan di komunitas Rumah Belajar Sahaja. Melalui komponen komunikasi sebuah peristiwa komunikasi dapat diidentifikasi. Peristiwa komunikasi yang teridentifikasi antara lain pada saat pengajar mengajak anak jalanan belajar, kegiatan belajar, dan penerapan peraturan-peraturan di komunitas Rumah Belajar Sahaja.

3. Pola komunikasi yang terbentuk di komunitas Rumah Belajar Sahaja yaitu pengajar melakukan pendekatan ke anak jalanan, anak jalanan harus melakukan peraturan komunitas Rumah Belajar Sahaja, pengajar melakukan komunikasi secra koersif dan tegas, memberikan materi belajar yang anak-anak jalanan suka, Memberikan makan dan minum kepada anak jalanan yang melaksanakan peraturan Rumah Belajar Sahaja.

\section{DAFTAR PUSTAKA}

Budyanta, M. (2012). Teori Komunikasi Antapribadi. Jakarta: Kencana Prenada Media Group.

Iriantara, Y. (2007). Community Relations: Konsep dan Aplikasinya. Bandung: Simbiosa Rekatama Media.

Kuswarno, E. (2011). Etnografi Komunikasi. Bandung: Widya Padjajaran. 
Mondry, E. (2008). Pemhaman Teori dan Praktik Jurnalistik. Bogor: Ghalia Indonesia Mulyana, D. (2007). Ilmu Komunikasi Suatu Pengantar. Bandung: PT Remaja Rosda Karya. Mulyana, D. (2008). Metodologi Penelitian Komunikasi. Bandung: Remaja Rosda Karya. Sardiman. (2007). Interaksi dan Motivasi Belajar Mengajar: Bandung: Rajawali PersA.M. Shalahuddin, O. (2000). Anak Jalanan Perempuan. Semarang: Yayasan Setara-TerredesHommes- Germany.

Soekanto, S. (2001). Sosiologi: Suatu Pengantar. Jakarta: Raja Grafindo Persada.

Sudjana, N. (2004). Dasar-dasar Proses Belajar Mengajar. Bandung: Sinar Baru Algensido Offset. 
POLA KOMUNIKASI KOMUNITAS RUMAH BELAJAR SAHAJA BANDUNG

Dwi Rizqi Anta \& Arie Prasetio 